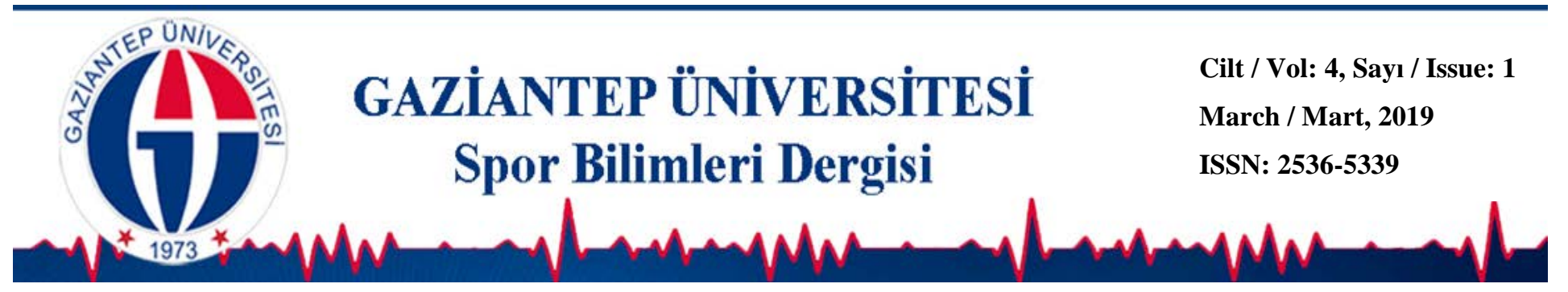

\title{
Kadın Çalışanların Yaşam Doyumu İle Boş Zaman Engelleri Arasındaki İlişki: Akdeniz Üniversitesi Örneği
}

\section{Emine Bal TURAN ${ }^{1}$ (D) Doğukan Batur Alp GÜLŞEN ${ }^{1 *}$ (D) $\quad$ Mehmet BİLALOĞLU ${ }^{1}$ (D)}

\author{
${ }^{1}$ Akdeniz Üniversitesi, Spor Bilimleri Fakültesi, ANTALYA
}

DOI: $10.31680 / g a u n j s s .479340$

Orijinal Makale / Original Article

Geliş Tarihi / Received: 11.06.2018～Kabul Tarihi / Accepted: 11.03.2019Ｙ Yayın Tarihi / Published: 22.03.2019

\section{Öz}

Akdeniz Üniversitesi işçi ve memur statüsünde çalışan kadınların yaşam doyumları ile boş zaman engelleri arasındaki ilişkinin belirlenmesi çalışmanın amacını oluşturmaktadır. Araştırma grubunu Akdeniz Üniversitesinde memur ve işçi statüsünde çalışan toplam 190 (yaş ortalaması $33 \pm 5.8$ ) kadından oluşmaktadır. Araştırma kapsamında araştırmacı tarafından oluşturmuş olan kişisel bilgi formu ayrıca yaşam doyumu ölçeği ve boş zaman engelleri ölçeği kullanılmıştır. Verilerin analizin de, pearson korelasyon ve frekans analizi uygulanmıştır. Yapılan analiz sonucunda katılımcıların boş zaman engelleri ile yaşam doyumu arasında negatif ilişki görülmüştür ( $r=-.24$; $\mathrm{p}$ <.05). Yaşam Doyumu ile Boş Zaman Engelleri arasındaki ilişkiye bakıldığında özellikle boş zaman engelleri alt boyutlarından; ilgi eksikliği alt boyutuyla $(r=-.24 ; p<0.01)$, bilgi eksikliği alt boyutuyla $(r=-.21 ; p<0.01)$ ve birey psikolojisi $(r=-.17 ; p<0.01)$, alt boyutlarında negatif ilişki görülmüştür. Bu ilişki doğrultusunda katılımcıların zaman, tesis ya da arkadaş eksikliği sebeplerinden kaynaklanmadığı serbest zamanının değerlendirmedeki unsurların bireyin kendi içsel motivasyonuna bağlı olduğu düşünülmektedir.

Anahtar kelimeler: Çalışma Hayatı, Kadın, Boş Zaman Engelleri, Yaşam Doyumu

\section{The Relationship Between the Life Satisfaction and Leisure Constraints of Women Employees: Study of Akdeniz University}

\begin{abstract}
The aim of this study was to determine the relationship between life satisfaction and leisure constraints of Akdeniz University women employees. A total of 190 (mean age: 33 \pm 5.8 ) women participated in this study. As a data collection instruments, personal information form created by researcher, life satisfaction scale and leisure constraints scale were used. Pearson correlation and frequency analysis were applied to the data analysis. As a result of the analysis, there was a negative correlation between leisure constraints and life satisfaction $(r=-.24 ; p$ $<0.05)$. This relationship is mainly related to leisure constraints's sub-dimensions; lack of interest sub-dimension $(r=-.24 ; p<0.01)$, lack of knowledge sub-dimension ( $r=-.21 ; p<0.01)$, and individual psychology sub-dimension $(r=-.17 ; p<0.01)$. According to this relationship, participants' leisure activities participation status is not due to the reasons of facilities or lack of friends. It is thought that the elements in the lesiure activities are dependent on the individual's intrinsic motivation.
\end{abstract}

Keywords: Work life, Female, Leisure Constraints, Life Satisfaction

\footnotetext{
*Sorumlu Yazar: Doğukan Batur Alp GÜLŞEN

E-mail: dogukan_gulsen@hotmail.com

* 1. Uluslararası Rekreasyon ve Spor Yönetimi Kongresinde Sözel Bildiri Olarak Sunulmuştur.
} 


\section{Giriş}

Günümüzde insanlar temel ihtiyaçların yanı sıra işten arta kalan sürelerde kendilerine zaman ayırma konusunda özenli davranmaya başladıkları görülmektedir. Çalışma hayatında kadın, her statü ve konumda görülmektedir. Fakat gelişmekte olan toplumlarda kadınlara yüklenen toplumsal rollerin çok fazla olmasından dolayı, iş hayatlarının dışında kendilerine ayıracakları zaman ve motivasyon konusunda sıkıntı yaşadıkları düşünülmektedir.

Çalışan kadınlar, iş yaşamlarında görev tanımları içerisinde yer alan işleri tamamladıktan sonra ev yaşamlarına döndüklerinde aslında bitti sanılan iş yüklerinin hala devam ettiği bilinmektedir. Bunlar; yemek yapmak, temizlik yapmak varsa çocukların bakımı gibi işler kadınlara yüklenen diğer görevlerdir. Bu açılardan bakıldığında peki kadın boş zamanlarında kendisine ne kadar vakit ayırabilmektedir? Engelleri ortadan kaldırıp vakit ayırabildiğinde rekreatif etkinliklerde ne derece etkin olarak yer alabiliyor? Vakit ayırdığı düşünüldüğün de kendisin de o enerjiyi bulabiliyor mudur? Çalışan kadın boş zaman aktiviteleri için zaman ayırdığında istenilen ya da beklenilen düzeyde bir yaşam doyumu yaşayabilmekte midir?

$\mathrm{Bu}$ sorular ve düşünceler doğrultusunda Akdeniz Üniversitesi' $\mathrm{n}$ de işçi ve memur statüsünde çalışan kadınların boş zaman engelleri ve yaşam doyum arasındaki ilişkinin incelenmesi araştırmanın temel amacını oluşturmaktadır.

\section{Boş Zaman ve Boş Zaman Engelleri}

Boş zaman kavramı, çağımızda gelişen sanayi toplumunun yapısal bir özelliğini ve toplum tipinin bir ürününü oluşturmaktadır. Boş zaman kavramını kültürel farklılıkları gözetmeden değerlendirmek oldukça zordur (Öztürk, 2013). Boş zaman konusu disiplinler arası bir konu olması ile birlikte her geçen gün değerinin biraz daha artması birçok araştırmacının dikkatini çekmiş ve incelenmeye başlanmıştır.

Kemp ve Pearson (1997), boş zaman kavramını dinlenme, çalışma, beslenme vb. zorunlu işler için ayrılan zaman dilimi olarak tanımlarken önemli olanın boş zaman diliminde kişilerin kaliteli etkinlikler içerisinde bulunarak zamanı daha verimli şekilde geçirmesi olduğunu belirtmiştir (Gürbüz ve Karaküçük 2007).

Boş zaman, bireyin kendisi için bütün engelleri ortadan kaldırdığı, kişinin özgür iradesi ile seçtiği bir etkinlikle uğraştığı, kendi isteği ve belirlediği zaman dilimlerindeki etkinlikler, uğraşlar olarak tanımlanmaktadır (Bakır, 1990). Boş zaman içerisinde bireyin katılımını engelleyen durumlar ortaya çıkmaktadır. 
Engel kavramı boş zaman literatürüne, kişilerin boş zamanlarında rekreatif etkinliklere katılımına engel teşkil eden ve ya kısıtlayan ve birey tarafından da algılanan sebepleri ifade etmektedir (Öztürk, 2013).

Günümüz yaşam koşulları, bireyleri huzur ve mutluluğu yakalamak adına boş zaman faaliyetlerine itmiştir ve bununla birlikte boş zaman aktivitelerine olan intiyaçlarda paralel olarak artış göstermiştir. İhtiyacın artması bir yana insanların ve toplumların sağlığı için önemi kabul edilen bu tür etkinliklere katılımın kısıtlı olması ya da farklı nedenler ile katılımın engellendiğini bir çok araştırma bulgusunda karşımıza çıkmaktadır (Alexandris ve Carroll, 1999).

\section{Yaşam Doyumu}

Mutluluk olarak literatüre geçmiş olan yaşam doyumu, insanlık tarihi boyunca dikkat çeken bir konu olmuştur. Günlük yaşamda çok kez kullanılmakta olan mutluluk kavramını tanımlamak oldukça güç olabilmektedir (Yetim, 1991). Bireylerin istek, arzu ve beklentilerinin karşılanması sonucunda meydana gelen hissi doyum olarak tanımlamak mümkündür (Deniz ve Yılmaz, 2004). 1961 yılında Neugarten' in yaşam doyumunu; bireylerin istekleri ve sahip oldukları arasındaki kıyaslama sonucu olarak tanımlamışır (Acar, 2009). Tanımdan yola çıkarak yaşam doyumunun bireylerin isteklerine ulaşabilmesi ile bağlantııdır (Bradley ve Crowny, 2004). Yaşam doyumu bu istekler sonucunda bireylerin hayatlarından memnun olma düzeylerini ortaya koymaktadır.

Yaşam doyumu; bireyin yaşam kalitesini, pozitif gelişim derecesi olarak tanımlanmaktadır (Veenhoven, 1996).

Kuramlar incelendiğinde yaşam doyumunun tanımı farklılıklar göstermiş olsa da bilişsel kuram doğrultusunda birçok araştırmacıya göre, bireyin yaşam standartlarına ilişkin bilişsel yargısı olarak tanımlanmıştır (Diener ve ark. 1985). Bireylerin hayatlarında kendileri için koymuş olduğu hedeflere ne kadar ulaşabildiğine odaklanmaktadır. Bireylerin yaşadığı standart ile yaşamak istediği standartlar arasında ki fark azaldıkça yaşam doyumlarının yükseleceği belirtilmektedir (Diener, 2000). Bireylerde yaşam doyumu ne kadar yüksek olursa günlük hayatında yapmış olduğu aktivitelerden de doğru orantıda o kadar yüksek haz duyacağı belirtilmektedir (Karataş, 1988).

Yaşam doyumunu etkileyen birçok faktör bulunmaktadır. Bu faktörleri 1978 yılında Flanagan 10 madde ile sıralamıştır. Bunlar; 
- Sosyalleşme

- Başka bireylere faydalı olabilme

- Eğlenceli aktiviteler içerisinde bulunmak (müzik dinleme, sinema, kitap okuma)

- Kendine güven

- Öğrenme süresinde aktif olmak

- Yakın çevre ilişkileri

- Düzenli devam edilen bir işe sahip olmak

- Kendini anlayabilmek

- Çocuk sahibi olup ve yetiştirebilmek

- Karı koca ilişkisindeki samimiyet olarak tanımlanmaktadır (Gülcan, 2014).

Yaşam doyumunun, kadın ve erkek açısından aralarında önemli fark yoktur. Cinsiyet tek başına yaşam doyumunu etkilemezken, bazı demografik değerler açısından anlamlı fark ortaya çıkmıştır (Köker, 1991). Bu bağlamda araştırmamızın amacı; Akdeniz Üniversitesinde farklı statülerde (işçi, memur) çalışan kadın çalışanların yaşam doyumları ile boş zaman engelleri arasındaki ilişkinin incelenmesidir.

\section{Yöntem}

\section{Araştırma Modeli}

Akdeniz Üniversitesin de işçi ve memur statüsünde çalışan kadınların yaşam doyumları ile boş zaman engelleri arasındaki ilişkinin incelenmesidir. Bu araştırma da, ilişkisel araştırma türlerinden tarama model kullanılmışıı. Araştırmada nicel yöntemlerden anket uygulama tekniği kullanılmıştır.

\section{Araştırma Grubu}

Araştırma evrenini Akdeniz Üniversitesi oluşturmuştur. Çalışmaya Akdeniz Üniversitesi'nde işçi ve memur statüsünde çalışan 20-55 yaş aralığında (Ort yaş $=33,15$ Ss $=5,84) 190$ birey katılmıştır.

\section{Veri Toplama Araçları}

\section{Yaşam Doyum Ölçeği}

Bireylerin, yaşam doyum düzeylerini belirlemede, Diener ve ark. (1985) tarafından geliştirilen, Köker (1991) tarafından Türkçeye uyarlanan 'Yaşam Doyum 
Ölçeği' kullanılmıştır. 5 madden oluşan ölçek 7'li likert tipinde hazırlanmış, puanlama da buna göre yapılmıştır. Likert seçenekleri "Kesinlikle Katılmıyorum (1)", "Katılmıyorum (2)", "Kısmen Katılmıyorum (3)", "Kararsızım (4)", "Kısmen Katılıyorum (5)", "Katılıyorum (6)" ve "Kesinlikle Katılıyorum (7)" şeklinde sıralanmıştır. Ölçekten alınabilecek en yüksek puan ise 35' tir. Bu çalışma için ölçeğin toplam iç tutarlıık katsayısı $.85^{\prime}$ tir.

\section{Boş Zaman Engelleri Ölçeği}

Çalışmada veri toplama aracı olarak Boş Zaman Engelleri Ölçeği- 18 Alexandris ve Carroll (1997) tarafından geliştirilen, Gürbüz ve Karaküçük (2007) tarafından Türkçeye uyarlanan, Gürbüz ve diğerleri (2012) tarafından kısa formu oluşturulan 'Boş Zaman Engelleri Ölçeği18' den oluşmaktadır (Gürbüz ve Karaküçük, 2007) Bu araştırmada kullanılan ölçek formu 18 madde ve 6 alt boyuttan oluşan 4'lü likert tipi bir ölçektir. Bu alt boyutlar; Birey Psikolojisi , Bilgi Eksikliği, Tesis, Arkadaş Eksikliği, Zaman ve İlgi Eksikliği biçimindedir. Ölçek maddeleri (1) "Kesinlikle Önemsiz" ve (4) "Kesinlikle Önemli" biçiminde sıralanmakta ve puanlanmaktadır. Bu çalışma için ölçeğin toplam iç tutarlıık katsayısı .76 ' tır.

\section{Verilerin Analizi}

Araştırmada verilerinin analizinde yapılan istatistiksel analizler, SPSS 22 istatistik paket programı kullanılmışır. Verilerin değerlendirilmesinde betimsel istatistik için yüzde (\%) ve frekans (f) kullanılmıştır. İlişki incelemesi için ise Pearson Korelasyon analizi kullanılmıştır.

Tablo 1. Katılımcıların Betimsel İstatistikleri

\begin{tabular}{ccc}
\hline Medeni Durum & $\mathbf{f}$ & \% \\
\hline Evli & 132 & 69.5 \\
Bekar & 58 & 30.5 \\
Total & 190 & 100,0 \\
\hline Çalışma Durumu & $\mathbf{f}$ & $\%$ \\
\hline İşçi & 77 & 41.2 \\
Memur & 113 & 58.8 \\
Total & 190 & 100,0 \\
\hline
\end{tabular}

Tablo 1 incelendiğinde araştırmaya katılan bireylerin medeni durumları ve memur-işçi değişkenine göre çalışma durumları görülmektedir. Araştırmaya katılan bireylerin \%69.5'i (132) evli, \%30.5', (58) bekar olduğu görülmektedir. 
Turan, EB., Gülşen, DBA., Bilaloğlu, M. (2019). Kadın Çalışanların Yaşam Doyumu İle Boş Zaman Engelleri Arasındaki İlişki: Akdeniz Üniversitesi Örneği. Gaziantep Üniversitesi Spor Bilimleri Dergisi, 4(1), 104-114.

Çalışma durumlarına bakıldığında araştırmaya katılan bireylerin \%41.2'si (77) işçi sınıfında çalışırken, \%58.8’i (113) memur sınıfında çalıştığı görülmektedir.

\section{Bulgular}

Tablo 2. Meslek değişkenine göre T-testi analiz sonuçları

\begin{tabular}{|c|c|c|c|c|c|c|}
\hline & Cinsiyet & $\mathrm{N}$ & Ortalama & $\begin{array}{l}\text { Standart } \\
\text { Sapma }\end{array}$ & $T$ & $p$ \\
\hline \multirow{2}{*}{$\begin{array}{l}\text { Bilgi Eksikliği } \\
\text { Alt Boyutu }\end{array}$} & Memur & 113 & 2,53 & ,644 & \multirow{2}{*}{2,078} & \multirow{2}{*}{, $039 *$} \\
\hline & İşçi & 77 & 2,74 & 698 & & \\
\hline Zaman & Memur & 113 & 2,94 & ,617 & \multirow[b]{2}{*}{2,118} & \multirow[b]{2}{*}{, $036^{\star}$} \\
\hline $\begin{array}{c}\text { Eksikliği Alt } \\
\text { Boyutu }\end{array}$ & İşçi & 77 & 2,76 & ,556 & & \\
\hline
\end{tabular}

Araştırmaya katılan katılımcıların meslek değişkenlerine göre boş zaman engelleri alt boyutlarına göre istatistiksel olarak bir fark olup olmadığını belirlemek için bağımsız örneklem t testi analizi yapılmıştır.

Yapılan analiz sonucunda bilgi eksikliği alt boyutunda ve zaman ve ilgi eksikliği alt boyutlarında istatistiksel olarak anlamlı farklılık tespit edilmiştir. 
Tablo 3. Yaşam Doyumu ve Boş Zaman Engelleri Korelasyon Sonuçları

\begin{tabular}{|c|c|c|c|c|c|c|c|c|c|}
\hline & & $\begin{array}{c}\text { YD } \\
\text { Toplam }\end{array}$ & $\begin{array}{c}\text { Birey } \\
\text { Psi }\end{array}$ & $\begin{array}{r}\text { Bilgi } \\
\text { Eksik. }\end{array}$ & Tesis & $\begin{array}{c}\text { Ark. } \\
\text { Eksik. }\end{array}$ & $\begin{array}{c}\text { Zaman } \\
\text { Eksik. }\end{array}$ & $\begin{array}{c}\text { İlgi } \\
\text { Eksik. }\end{array}$ & $\begin{array}{c}\text { BEÖ } \\
\text { Toplam }\end{array}$ \\
\hline \multirow[t]{3}{*}{ YDTP } & $r$ & 1 &,$- 178^{*}$ &,$- 218^{\star *}$ &,- 049 &,- 043 & ,027 &,$- 246^{* *}$ &,$- 248^{* *}$ \\
\hline & $\mathrm{p}$ & & ,014 & ,002 &, 505 &, 553 &, 712 & ,001 & ,001 \\
\hline & $\mathrm{N}$ & & 190 & 190 & 190 & 190 & 190 & 190 & 190 \\
\hline \multirow[t]{3}{*}{ BireyPsi } & $r$ & & 1 & ,136 &, $147^{*}$ &,- 015 &,- 079 & ,093 &, $487^{* *}$ \\
\hline & $\mathrm{p}$ & & & ,061 & ,044 & ,841 & ,276 & ,202 & ,000 \\
\hline & $\mathrm{N}$ & & & 190 & 190 & 190 & 190 & 190 & 190 \\
\hline \multirow{3}{*}{$\begin{array}{l}\text { Bilgi } \\
\text { Eksikliği }\end{array}$} & $r$ & & & 1 &, $372^{* *}$ &,- 033 &,- 005 &, $163^{*}$ &, $563^{* *}$ \\
\hline & $\mathrm{p}$ & & & & ,000 & ,655 & ,940 & ,025 &, 000 \\
\hline & $\mathrm{N}$ & & & & 190 & 190 & 190 & 190 & 190 \\
\hline \multirow[t]{3}{*}{ Tesis } & $r$ & & & & 1 &,$- 253^{\text {** }}$ & ,093 &, $267^{* *}$ &, $554^{* *}$ \\
\hline & $\mathrm{p}$ & & & & & ,000 & ,203 & ,000 &, 000 \\
\hline & $\mathrm{N}$ & & & & & 190 & 190 & 190 & 190 \\
\hline \multirow{3}{*}{$\begin{array}{l}\text { Ark. } \\
\text { Eksikliği }\end{array}$} & $r$ & & & & & 1 & ,106 & ,054 &, $316^{* *}$ \\
\hline & $p$ & & & & & & ,145 & ,460 &, 000 \\
\hline & $\mathrm{N}$ & & & & & & 190 & 190 & 190 \\
\hline \multirow[t]{3}{*}{ Zaman } & $r$ & & & & & & 1 &, $170^{*}$ &, $398^{* *}$ \\
\hline & $\mathrm{p}$ & & & & & & & ,019 & ,000 \\
\hline & $\mathrm{N}$ & & & & & & & 190 & 190 \\
\hline \multirow[t]{3}{*}{ İlgiEks } & $r$ & & & & & & & 1 &, $578^{* *}$ \\
\hline & $\mathrm{p}$ & & & & & & & &, 000 \\
\hline & $\mathrm{N}$ & & & & & & & & 190 \\
\hline
\end{tabular}

Tablo 2'de Yaşam Doyumu ile Boş Zaman Engelleri ölçeğinin alt boyutları arasında ki ilişki incelenmiştir. Yaşam Doyumu ile Birey Psikolojisi ( $r=,-17)$, Bilgi Eksikliği $(r=,-21)$ ve İlgi Eksikliği $(r=,-24)$ alt boyutlarında düşük düzeyli ve negatif yönde anlamlı bir ilişki saptanmıştır.

Tesis Eksikliği, Arkadaş Eksikliği ve Zaman Eksikliği alt boyutlarında anlamlı bir ilişki saptanmamıştır. Yaşam Doyumu ve Boş Zaman Engelleri arasında negatif bir ilişki saptanmıştır $(r=-.24 ; p<0.05)$.

\section{Tartışma ve Sonuç}

Boş Zaman Engelleri alt boyutları puanları ile Yaşam Doyumu puanları arasındaki ilişkiyi ortaya koyabilmek için yapılmış olan Pearson Korelasyonu analiz 
sonucu: Birey Psikolojisi, Bilgi Eksikliği, İlgi Eksikliği alt boyutları ve Boş Zaman Engelleri Ölçeği toplam puanı ile Yaşam Doyumu arasında negatif yönlü bir ilişki olduğu saptanmıştır. Korelasyon Sonucu; Birey Psikolojisi alt boyutu puanı $(r=,-17 \mathrm{p}$ $<0,05)$; Bilgi Eksikliği Alt Boyutu puanı $(r=,-1, p<0,05)$; İlgi Eksikliği alt boyutu puanı $(r=,-24, p<0,001)$; BZEÖ toplam puanı $(r=,-24, p<0,001)$ alt boyutlarında yaşam doyumu ile anlamlı düzeyde açıklandığı görülmektedir. Sonuç olarak; Boş Zaman Engellerinin Yaşam Doyumu ile ilişkili olduğu vurgulanmaktadır.

Pala ve Dinç (2013)'in kamu personelinin serbest zaman engellerine ilişkin yaptığı çalışmada "Birey Psikolojisi" alt boyutunda anlamlı farklılıklar olduğu belirtilmiştir. Bu anlamda Pala ve Dinç (2013) tarafından yapılan çalışma sonuçları ile bu çalışma sonuçları paralellik göstermektedir. Bu bağlamda kadın çalışanların yaşam doyumu ve boş zaman engellerin de anlamlı ilişki gösteren alt boyutlarına bakıldığında, boş zamanını engelleyen unsurların, ilgi eksikliğinden ve birey psikolojik durumundan kaynaklı olduğu görülmektedir. Bu unsurlar neticesinde kadınların bir etkinlik veya aktiviteye katııındaki içsel motivasyonu kendilerinde yakalayamadıkları düşünülmektedir.

Kaya (2011) tarafından beş farkı üniversitede yapılan çalışmada üniversitede tesis ve olanakların yeterli olmadığı için rekreatif etkinliklere öğrencilerin katılmadığı sonucuna ulaşılmışır. Amin ve ark. (2011) tarafından yapılan çalışma bulgularında ise rekreatif etkinliklere katııımın önündeki engellerin genellikle tesis ve zaman yetersizliği ile ilgili olduğu sonucuna ulaşılmıştır. Emir (2012) tarafından yapılmış olan Rekreatif Etkinliklere Katıımın Önündeki Engellerin Belirlenmesi; Üniversite Öğrencileri Örneği adlı çalışma bulgularında rekreatif etkinliklere katılımın tesis ve zaman yetersizliği ile ilgili olduğu gözlenmiştir. Bu çalışmalara paralel olarak Gürbüz ve ark., (2010) yapmış oldukları Rekreasyonel Aktivitelere Katıımın Önündeki Algılanan Engel Farkın İncelenmesi: Ankara Örneği adlı çalışma bulgularına göre genel olarak tesis yetersizliği ile ilgili olduğu sonucuna ulaşılmıştır. Çolakoğlu (2005) tarafından yapılmış olan Üniversite Öğretim Elemanlarının Boş Zaman Alışkanlıklarını Değerlendirmeleri Üzerine Bir Araştırma isimli çalışma bulguları incelendiğinde tesis yetersizliği sonucu boş zamanlarında rekreatif etkinliklere katılamadıkları sonucuna ulaşılıışır.

Öztürk (2016) tarafından yapılan çalışmada Alışveriş Merkezi Çalışanlarının Rekreasyon Etkinliklerine Katılımlarının Önündeki Engellerin Belirlenmesi adlı 
çalışma sonucunda boş zamanlarında rekreatif etkinliklere katılımın düşük olmasının temel nedeninin tesis yetersizliği olduğu sonucuna ulaşılmıştır.

Çalışmamıza benzer şekilde; Öztürk (2013) tarafından yapılan çalışmada sanayi çalışanlarının medeni durum değişkenlerine göre bekar bireylerin evli bireylere göre rekreatif etkinliklerine daha fazla katıldıkları sonucuna ulaşıımıştır.

Brown ve Frankel (1993) tarafından 18 ile 70 yaşları arasındaki 685 kişi ile yapılan çalışmada serbest zaman doyumu ile yaşam doyumu arasında orta düzeyde korelasyon bulunmuştur. Kinnney ve Coyle (1992) yılında yapmış oldukları çalışmada ise yaş ilerledikçe serbest zaman doyumunun serbest zaman doyumunuda arttırdığı görülmüştür.

\section{Kaynaklar}

Acar, M. (2009). Zihinsel ve Fiziksel Özürlü Çocuğa Sahip Anne ve Babaların Yaşam Doyum ve Umutsuzluk Düzeylerinin İncelenmesi. Yüksek Lisans Tezi. Konya: SÜ. Sağlık Bilimleri Enstitüsü.

Alexandris, K., Carroll, B. (1999). Constranins On Recreational Sport Porticipation İn Adults İn Greece: Implications For Providing And Managing Sport Services, journal Of Sport management, 13 (4), 317-332

Amin, T. T., Suleman, W. Ali, A., Gamal, A., Al, W.A. (2011). "Pattern, Prevalence, and Perceived Personal Barriers Toward Physical Activity Among Adult Saudis İn Al-Hassa, KSA", Journal of Physical Activity and Health, 8(6), 775-84.

Bradley, R. H., Corwyn, R. F. (2004). Life Satisfaction Among European American, African American, Chinese American, Mexican American, And Dominican American Adolescents. International Journal Of Behavioral Developmen. 28(5), 385-400.

Brown, B., Frankel, G. (1993) Activity Trough the Years: Leisure. Leisure Satisfaction and Life Satisfaction. Sociology of Sports Journal. 10. 1-17

Çolakoğlu, T. (2005). Üniversite Öğretim Elemanlarının Boş Zaman Alışkanlıklarını Değerlendirmeleri Üzerine Bir Araştırma, Gazi Eğitim Fakültesi Dergisi, 25 (1), 247-258.

Deniz, M.E., Yılmaz, E. (2004). Üniversite Öğrencilerinin Duygusal Zeka Yetenekleri ve Yaşam Doyumları Arasındaki İlişki. XIII. Ulusal Eğitim Bilimleri Kurultayı. Malatya: IÜ. Eğitim Fakültesi. 
Diener, E. (2000). Subjective Well- Being: The Science Of Happiness And A Proposal Fornational İndex. American Psychologist. 55, 34- 43.

Diener, E., Emmons, R., Larsen, R. J., Griffin, S. (1985). The Satisfaction With Life Scale. Journal of Personality Assessment. 49 (1), 71- 75.

Emir, E. (2012). Rekreatif Etkinliklere Katılımın Önündeki Engellerin Belirlenmesi: Üniversite Öğrencileri Örneği, Yüksek Lisans Tezi, Trabzon

Gülcan, A. (2014) Genç Yetişkinlerde İyimserliğin Mutluluk ve Yaşam Doyumu Üzerindeki Etkisinin İncelenmesi. Yüksek Lisans Tezi. İstanbul: FÜ. Sosyal Bilimler Enstitüsü

Gürbüz, B. ve Karaküçük, S. (2007). Boş Zaman Engelleri Ölçeği, Gazi Üniversitesi, Beden Eğitimi ve Spor Bilimleri Dergisi, 8(12), 3-10.

Gürbüz, B., Karaküçük, S. ve Sarol, H. (2010). Rekreasyonel Aktivitelere Katılımın Önündeki Algılanan Engel Farklılıklarının İncelenmesi: Ankara Örneği, 11. Uluslararası Spor Bilimleri Kongresi, Antalya.

Karataş, S.Ç. (1988). Yaşlılarda Yaşam Doyumunu Etkileyen Etmenler. Yayınlanmamış Yüksek Lisans Tezi. Ankara: HÜ. Sosyal Bilimler Enstitüsü.

Kaya, A. M. (2011). Üniversite Öğrencilerinin Rekreatif Faaliyetlere Yönelik Tutumları Ve Boş Zaman Motivasyonlarının Bazı Değişkenler Açısından İncelenmesi. (Yayınlanmamış yüksek lisans tezi). Cumhuriyet Üniversitesi Sağlık Bilimleri Enstitüsü, Sivas

Köker, S. (1991). Normal ve Sorunlu Ergenlerin Yaşam Doyum Düzeylerinin karşılaştırılması. Yüksek Lisans Tezi. Ankara.

Öztürk, H. (2013). Sanayi Çalışanlarının Rekreatif Aktivitelere Katılımlarının Örgütsel Bağlılık ve Tükenmişlik Düzeylerine Etkisi (Gaziantep Uygulaması), Doktora Tezi, Ankara.

Öztürk, H. (2016). The Obstacles Affecting Shopping Center Employees' Participation in Recreational Activities, J Soc Sci, 47(1), 41-48.

Pala, F., \& Dinç, S. C. (2013). Kamu kurumlarında görev yapan personelin serbest zaman etkinliklerine katılımını engelleyen faktörlerin belirlenmesi, 2. Rekreasyon Araştırmaları Kongresi, Aydın, Turkey, 632-637.

Veenhoven, R. (1996). The study of life satisfaction. In W. E. Saris, R. Veenhoven, A. C. Scherpenzeel, \& B. Bunting (Eds.), A comparative study of satisfaction with life in Europe (pp. 11-48). Budapest: Eötvös University Press. 
Turan, EB., Gülşen, DBA., Bilaloğlu, M. (2019). Kadın Çalışanların Yaşam Doyumu İle Boş Zaman Engelleri Arasındaki İlişki: Akdeniz Üniversitesi Örneği. Gaziantep Üniversitesi Spor Bilimleri Dergisi, 4(1), 104-114.

Yetim, Ü. (1991). Kişisel Projelerin Organizasyonu ve Örüntüsü Açısından Yaşam Doyumu. Doktora Tezi. İzmir. EÜ. Sosyal Bilimler Enstitüsü. 